\title{
Association between serum ferritin levels and clinical outcomes in maintenance hemodialysis patients: a retrospective single-center cohort study
}

Raku Son ${ }^{1}$, Takuya Fujimaru ${ }^{1 *}$ (D, Takeshi Kimura², Fumika Taki ${ }^{1}$, Miyuki Futatsuyama', Masahiko Nagahama ${ }^{1}$, Masaaki Nakayama ${ }^{1}$ and Yasuhiro Komatsu ${ }^{1,3}$

\begin{abstract}
Background: Ferritin is a well-known marker of iron deficiency anemia, but the target in maintenance hemodialysis (MHD) patients remains controversial. This study examined the association between baseline ferritin levels and clinical outcomes.

Methods: We retrospectively collected the data of outpatients on MHD for 5 years at St. Luke's International Hospital from July 2009. Patients with baseline ferritin levels of $>100 \mathrm{ng} / \mathrm{mL}$ in June 2009 were defined as the highferritin (HF) group and the remaining patients as the low-ferritin (LF) group. The primary endpoint was all-cause mortality. The secondary endpoints included cardiovascular events and infection-related hospitalizations. Log-rank test and Cox proportional hazard analysis were performed.

Results: Of 116 patients (age, $65.4 \pm 13.4$ years, $70 \%$ males), 29 (25\%) and 87 (75\%) belonged to the HF and LF groups, respectively. During the follow-up period of 1825 (interquartile range 819-1825) days, 38 patients (23 in the HF and 15 in the LF groups) died. According to the Kaplan-Meier survival curves, the HF group had significantly poor survival compared with the LF group $(p=0.0089)$. After adjusting for age, sex, vintage of hemodialysis, $C$ reactive protein levels, and history of cardiovascular events, the hazard ratio (HR) for the HF group was 2.49 (95\% confidence interval $(\mathrm{Cl}), 1.21-5.12)$. The multivariate analysis of cardiovascular events revealed a similar result with statistical significance (HR 2.69; 95\% Cl 1.12-6.46). Infection-related hospitalizations did not exhibit any statistically significant difference.
\end{abstract}

Conclusions: In MHD patients, ferritin levels $>100 \mathrm{ng} / \mathrm{mL}$ is associated with increased rates of all-cause mortality and cardiovascular events.

Keywords: Hemodialysis, Anemia, Ferritin, Prognosis, Cardiovascular events

\section{Introduction}

The management of anemia is important in maintenance hemodialysis (MHD) patients and is mainly achieved by the administration of iron and erythropoietin-stimulating agents (ESAs) [1]. MHD patients are predisposed to iron deficiency due to residual blood loss during hemodialysis treatment and frequent blood sampling [2]. Serum ferritin

\footnotetext{
* Correspondence: t.fujimaru1217@gmail.com

'Department of Nephrology, St. Luke's International Hospital, 9-1 Akashi-cho, Chuo-ku, Tokyo 104-8560, Japan

Full list of author information is available at the end of the article
}

is an established marker for detecting absolute iron deficiency. However, the optimal target ferritin level in MHD patients remains controversial. Recommendations for iron supplementation with ESA treatment differ among guidelines: according to the Kidney Disease: Improving Global Outcomes guideline [1], iron supplementation should be considered when transferrin saturation (T-SAT) is $\leq 30 \%$ and ferritin is $\leq 500 \mathrm{ng} / \mathrm{mL}$, whereas the Kidney Disease Outcomes Quality Initiative recommends maintaining T-SAT at $>20 \%$ and ferritin at $>200 \mathrm{ng} / \mathrm{mL}$ [3]. The Japanese Society for Dialysis Therapy sets the target ferritin

(c) The Author(s). 2019 Open Access This article is distributed under the terms of the Creative Commons Attribution 4.0 International License (http://creativecommons.org/licenses/by/4.0/), which permits unrestricted use, distribution, and 
level at $100 \mathrm{ng} / \mathrm{mL}$, which is much lower than that described in other recommendations. Iron is given when $\mathrm{T}$-SAT is $\leq 20 \%$ and ferritin is $\leq 100 \mathrm{ng} / \mathrm{mL}$ [4]. This practice was recently revised, and iron supplementation is currently considered when T-SAT is $\leq 20 \%$ or ferritin is $\leq$ $100 \mathrm{ng} / \mathrm{mL}$ [5].

Some observational studies have demonstrated a correlation between high ferritin levels and poor clinical outcomes in MHD patients, using a cut-off ferritin level of $600-1200 \mathrm{ng} / \mathrm{mL}$ [6-8]. However, two observational studies from Japan have provided evidence for a cut-off ferritin level of $100 \mathrm{ng} / \mathrm{mL}[9,10]$. Of the two, the Nishinomiya study reported increased mortality and a combined hazard ratio (HR) of mortality and cardiovascular events during an 8-year follow-up period [9], and the other study assessed the fluctuation of ferritin levels to demonstrate increased adverse events during a 2-year follow-up period [10]. Another study pointed out possible U-shape relation of ferritin levels and prognosis in MHD patients when stratified by inflammation [11]. In Japanese MHD patients, the most important causes of death are cardiovascular events and infections [12]. However, no study has directly specified the relationship between absolute ferritin levels and detailed causes of death, which may explain the increased mortality in hyperferritinemia.

This study was conducted to provide a better understanding of the relationship between high ferritin levels and detailed complications, including the top two causes of death (cardiovascular events and infection), using a cut-off ferritin level of $100 \mathrm{ng} / \mathrm{mL}$ over a long follow-up period in MHD patients.

\section{Materials and methods Patients}

All outpatients aged $>18$ years who were receiving MHD at St. Luke's International Hospital on July 1, 2009 were included in this study. Patients treated less frequently than three times per week or with a hemodialysis vintage of $<3$ months were excluded. Laboratory tests, including hemoglobin levels, iron concentration, total iron binding capacity (TIBC), and ferritin levels, were performed in June 2009 for all patients. Anemia was treated with weekly darbepoetin and/or ten consecutive doses of weekly intravenous saccharated ferric oxide $(40 \mathrm{mg})$. Treatment was adjusted based on the laboratory results of hemoglobin levels every other week and iron status every 3 months, which were determined by the physicians according to 2008 Japanese Society for Dialysis Therapy: Guidelines for Renal Anemia in Chronic Kidney Disease [4]. In the guideline, the target hemoglobin level was $10-12 \mathrm{~g} / \mathrm{dL}$, and saccharated ferric oxide was recommended only when T-SAT was $\leq 20 \%$ and the serum ferritin level was $\leq 100 \mathrm{ng} / \mathrm{mL}$. No oral iron supplements were used.

\section{Study design}

This was a single-center retrospective cohort study. Patients with baseline ferritin levels $>100 \mathrm{ng} / \mathrm{mL}$ in June 2009 were defined as the high-ferritin (HF) group, and the rest were defined as the low-ferritin (LF) group. Patients were followed for 60 months from July 1, 2009 to June 30, 2014, unless they received a kidney transplant or were lost to follow-up. Baseline characteristics that could influence the iron status or long-term prognosis in MHD patients were reviewed. Baseline clinical data, including age, gender, cause of end-stage renal disease (ESRD), hemodialysis vintage, body mass index (BMI), and histories of coronary artery diseases (CAD), arterial fibrillation, diabetes mellitus, hypertension, dyslipidemia, cardiovascular events [defined as acute cardiac infarction (AMI), cerebral infarction, or cerebral hemorrhage], gastrectomy, malignancy, positive fecal occult blood, liver disorders, and recent hospitalization within 3 months, were collected by reviewing medical records. Laboratory data that were measured in June 2009 included hemoglobin levels, iron concentration, TIBC, creatinine levels, BUN, calcium levels, phosphate levels, LDL-cholesterol levels, albumin levels, and C-reactive protein (CRP) levels. T-SAT was calculated as iron concentration divided by TIBC and calcium values were corrected based on serum albumin levels. The total ESA dose (darbepoetin) in the first month (July 2009), total intravenous iron dose per month in the first month (July 2009), and the $\mathrm{Kt} / \mathrm{V}$ were also calculated.

\section{Endpoints and statistics}

The primary endpoint was all-cause mortality. The secondary endpoints were cardiovascular events (AMI confirmed by coronary angiography and cerebral infarction or cerebral hemorrhage confirmed by computed tomography or magnetic imaging) and infection-related hospitalizations. Secondary endpoints were assessed based on the frequency with which they caused death in hemodialysis patients [12]. Data of patients who were transferred to another hospital were collected from the medical records.

Patient characteristics were analyzed using the $t$ test, chi-square test, and Fisher's exact test, as appropriate. We performed receiver operating characteristic (ROC) analysis to examine the validity of using cut-off level of serum ferritin $100 \mathrm{ng} / \mathrm{mL}$ based on the highest Youden index (sensitivity + specificity - 1) [13]. We used the Kaplan-Meier method to draw time-to-event curves and the log-rank test to compare the HF and LF groups. Cox proportional hazard analysis was performed for univariate and multivariate analysis. We chose age, gender, vintage of hemodialysis, CRP levels, and history of cardiovascular events as confounding factors based on previous studies [9] and the results of Cox proportional 
Table 1 Demographic, laboratory, and clinical characteristics

\begin{tabular}{|c|c|c|c|c|}
\hline & Total $(n=116)$ & $\mathrm{LF}(n=87)$ & $\mathrm{HF}(n=29)$ & $p$ value \\
\hline Serum ferritin, $\mathrm{ng} / \mathrm{mL}$ & $50.7(17.5-98.8)$ & $30(14.3-56.7)$ & $151(117.5-218)$ & \\
\hline Cohort time, day & $1825(819-1825)$ & $1825(1008-1825)$ & $1091(668.5-1825)$ & \\
\hline Age, year & $65.4 \pm 13.4$ & $64.8 \pm 13.5$ & $66.9 \pm 13.3$ & 0.47 \\
\hline Male $^{a}$ & $81(70 \%)$ & $59(68 \%)$ & $22(76 \%)$ & 0.49 \\
\hline \multicolumn{5}{|l|}{ Cause of ESRD } \\
\hline Diabetic nephropathy & $34(29 \%)$ & $26(30 \%)$ & $8(28 \%)$ & \\
\hline IgA nephropathy or chronic glomerulonephritis & $36(31 \%)$ & $25(29 \%)$ & $11(38 \%)$ & \\
\hline Nephrosclerosis & $12(10 \%)$ & $10(11 \%)$ & $2(6.9 \%)$ & \\
\hline Rapid progressive glomerulonephritis & $1(0.9 \%)$ & $1(1.1 \%)$ & $0(0 \%)$ & \\
\hline Polycystic kidney disease & $7(6.0 \%)$ & $6(6.9 \%)$ & $1(3.4 \%)$ & \\
\hline Others & $14(12 \%)$ & $10(11 \%)$ & $4(14 \%)$ & \\
\hline Unknown & $12(10 \%)$ & $9(10 \%)$ & $3(10 \%)$ & \\
\hline Hemoglobin, g/dL & $10.8 \pm 1.15$ & $10.9 \pm 1.08$ & $10.7 \pm 1.34$ & 0.49 \\
\hline Serum iron, $\mu \mathrm{g} / \mathrm{dL}$ & $55.5(38-73)$ & $54(35-73)$ & $56(45-79.5)$ & 0.12 \\
\hline $\mathrm{TIBC}, \mu \mathrm{g} / \mathrm{dL}$ & $271(235-309)$ & $284(251-318)$ & $234(207-257)$ & $<0.001$ \\
\hline T-SAT, \% & $20.4(14.8-27.3)$ & $17.9(13.3-24.6)$ & $25.7(19.7-34)$ & 0.0007 \\
\hline Intravenous iron ${ }^{a}$ & $27(23 \%)$ & $21(24 \%)$ & $6(21 \%)$ & 0.80 \\
\hline Iron dose, mg/month & $42.1 \pm 85.8$ & $45.5 \pm 92.1$ & $31.7 \pm 63.6$ & 0.46 \\
\hline$E S A^{a}$ & $100(86 \%)$ & $75(86 \%)$ & $25(86 \%)$ & 1.00 \\
\hline ESA dose, $\mu \mathrm{g} /$ week & $29.9 \pm 25.1$ & $30.2 \pm 24.7$ & $29.3 \pm 26.7$ & 0.87 \\
\hline HD vintage, month & $79(32-136)$ & $81(33-138)$ & $78(27-124)$ & 0.68 \\
\hline Kt/N (single pool) & $1.40(1.23-1.54)$ & $1.38(1.25-1.53)$ & $1.43(1.21-1.56)$ & 0.067 \\
\hline Serum creatinine, mg/dL & $11.9 \pm 3.04$ & $12.0 \pm 3.16$ & $11.5 \pm 2.66$ & 0.43 \\
\hline $\mathrm{BUN}, \mathrm{mg} / \mathrm{dL}$ & $64.9 \pm 16.0$ & $64.7 \pm 15.6$ & $65.5 \pm 17.3$ & 0.83 \\
\hline Serum calcium ${ }^{\mathrm{b}}, \mathrm{mg} / \mathrm{dL}$ & $9.33 \pm 0.67$ & $9.33 \pm 0.67$ & $9.35 \pm 0.70$ & 0.87 \\
\hline Serum phosphate, mg/dL & $5.3(4.73-5.3)$ & $5.4(4.9-6.3)$ & $5.0(4.0-5.45)$ & 0.001 \\
\hline $\mathrm{BMI}, \mathrm{kg} / \mathrm{m}^{2}$ & $21.6 \pm 3.50$ & $21.8 \pm 3.28$ & $21.4 \pm 4.07$ & 0.25 \\
\hline Serum albumin, g/dL & $3.95(3.72-4.10)$ & $4.0(3.8-4.1)$ & $3.9(3.65-4.1)$ & 0.22 \\
\hline LDL-cholesterol, mg/dL & $75(57.3-94.5)$ & $73(57-93)$ & $77(60.5-99)$ & 0.69 \\
\hline CRP, mg/dl & $0.07(0-0.35)$ & $0.05(0-0.14)$ & $0.30(0.02-0.77)$ & 0.003 \\
\hline History of $C A D^{a}$ & $31(27 \%)$ & $22(25 \%)$ & $9(31 \%)$ & 0.63 \\
\hline History of atrial fibrillation ${ }^{a}$ & $14(12 \%)$ & $10(11 \%)$ & $4(14 \%)$ & 0.22 \\
\hline History of diabetes mellitus & $38(33 \%)$ & $28(32 \%)$ & $10(34 \%)$ & 0.82 \\
\hline History of hypertension ${ }^{a}$ & $100(86 \%)$ & $73(84 \%)$ & $27(93 \%)$ & 0.35 \\
\hline History of dyslipidemia ${ }^{a}$ & $27(23 \%)$ & $20(23 \%)$ & $7(24 \%)$ & 1.00 \\
\hline History of CV events & $48(41 \%)$ & $34(39 \%)$ & $14(48 \%)$ & 0.38 \\
\hline History of gastrectomy ${ }^{a}$ & $6(5.2 \%)$ & $3(3.4 \%)$ & $3(10 \%)$ & 0.16 \\
\hline History of malignancy ${ }^{a}$ & $5(4.3 \%)$ & $4(4.6 \%)$ & $1(3.5 \%)$ & 0.34 \\
\hline Positive fecal occult blood ${ }^{a}$ & $19(16 \%)$ & $12(16 \%)$ & $7(25 \%)$ & 0.39 \\
\hline History of liver disorders ${ }^{a}$ & $14(12 \%)$ & $10(12 \%)$ & $4(14 \%)$ & 0.75 \\
\hline Recent hospitalization ${ }^{a}$ & $8(6.9 \%)$ & $4(4.6 \%)$ & $4(14 \%)$ & 0.11 \\
\hline
\end{tabular}

Values are reported as mean \pm standard deviation, median (interquartile range) or number (\%) as appropriate. Comparisons were made between the two stratified populations

$L F$ low-ferritin, $H F$ high-ferritin, ESRD end-stage renal disease, TIBC total iron binding capacity, T-SAT total iron binding capacity, ESA erythropoietinstimulating agent, $H D$ hemodialysis, $B M I$ body mass index, $C R P C$-reactive protein, $C A D$ coronary artery disease, $C V$ cardiovascular

${ }^{a}$ Analyzed by Fisher's exact test

${ }^{\mathrm{b}}$ Corrected using the following formula: Corrected calcium = serum calcium $+(4-$ serum albumin) $(\mathrm{g} / \mathrm{dL})$ when the albumin level is $<4 \mathrm{~g} / \mathrm{dL}$ 
Table 2 Detailed causes of death (n\%)

\begin{tabular}{llll}
\hline Cause of death & Total $(n=116)$ & LF $(n=87)$ & HF $(n=29)$ \\
\hline Death & 36 & 23 & 15 \\
CV events & $13(34 \%)$ & $6(26 \%)$ & $6(40 \%)$ \\
Infections & $12(32 \%)$ & $9(30 \%)$ & $6(40 \%)$ \\
Others & $9(24 \%)$ & $6(26 \%)^{\mathrm{a}}$ & $3(20 \%)^{\mathrm{b}}$ \\
Unknown & $2(5.3 \%)$ & $2(8.7 \%)$ & 0 \\
\hline
\end{tabular}

LF low-ferritin, HF high-ferritin, $C V$ cardiovascular

${ }^{a}$ Two cases of non-occlusive mesenteric ischemia, one case of ischemic colitis, one case of exacerbation of chronic obstructive pulmonary disease, one case of liver failure, and one case of cardiopulmonary arrest due to hemoptysis

${ }^{\mathrm{b}}$ Two cases of liver failure and one case of rupture of abdominal aortic aneurysm

hazard analysis. Alpha level of 0.05 was used in all analyses. All statistical analyses were performed using JMP version 9.0 (SAS Institute, Cary, NC).

\section{Results}

\section{Patients}

A total of 116 MHD patients were included in this study. The mean age was $65.4 \pm 13.4$ years, and 81 patients $(70 \%)$ were males. Of the cohort, 87 patients (75\%) had baseline ferritin levels of $\leq 100 \mathrm{ng} / \mathrm{mL}$ and were defined as the LF group. The remaining 29 patients $(25 \%)$ belonged to the HF group. The baseline demographic, laboratory, and clinical characteristics are shown in Table 1 . The vintage of MHD was approximately 80 months. A total of 27 patients (23\%) were receiving intravenous iron, 100 (86\%) were receiving darbepoetin, and 26 (22\%) were receiving both. The median serum ferritin level was $30 \mathrm{ng} / \mathrm{mL}$ in the LF group and $151 \mathrm{ng} / \mathrm{mL}$ in the HF group. The cause of ESRD was mainly diabetic nephropathy or chronic glomerulonephritis in both groups, with no significant difference. The treatment pattern of anemia was not significantly different between the LF and HF groups. Intravenous iron or ESA average dosage showed no significant differences. In terms of iron status, the TIBC was significantly higher in the LF group, whereas T-SAT was higher in the HF group. Serum phosphate levels were lower and CRP levels were higher in the HF group. No difference was noted in the past medical history, including history of malignancy, liver diseases, and recent hospitalization.

\section{Primary endpoint}

During the study period of 1825 (interquartile range 8191825) days, 38 of 116 patients (33\%) died [23 of 87 (26\%) in the LF and 15 of 29 (52\%) in the HF groups]. The details regarding the cause of death are shown in Table 2. Cardiovascular events were the second common cause of death in the LF group (6 of 23 events; $26 \%$ ) and the leading cause of death in the HF group (6 of 15 events; 40\%). Infection was

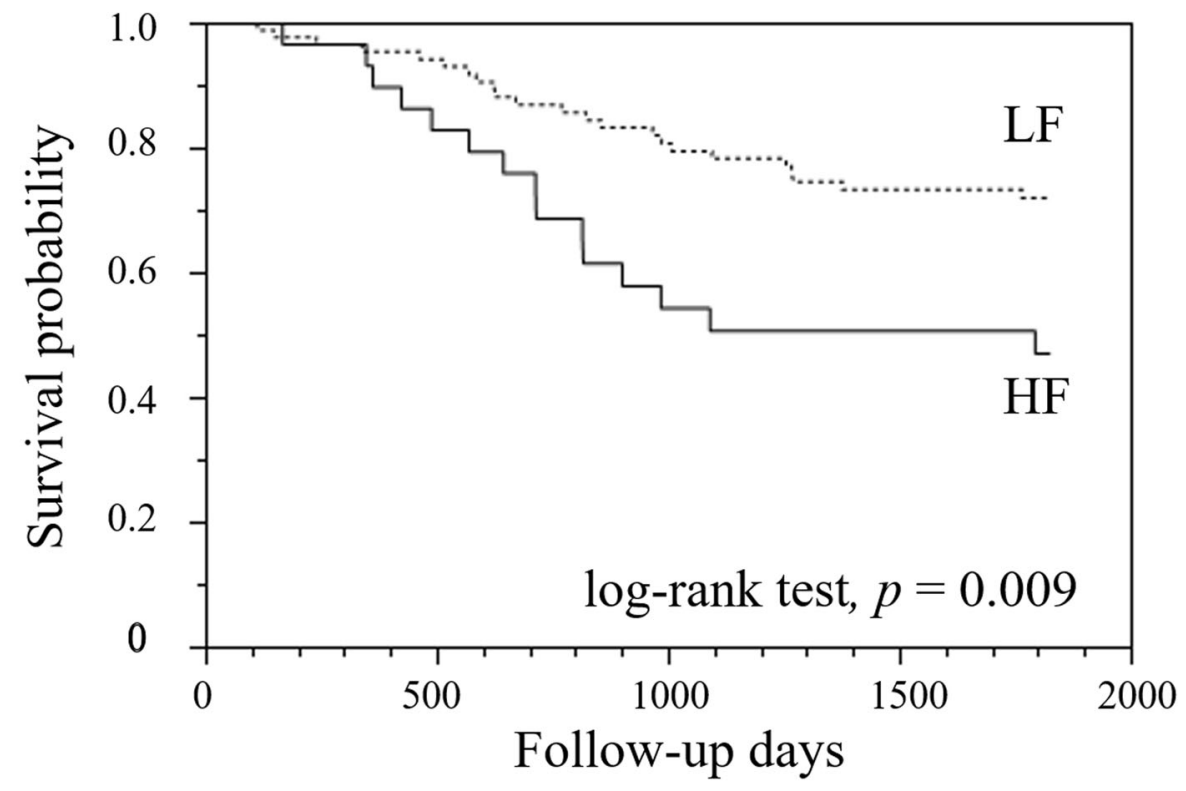

Number at risk

$\begin{array}{lllll}\text { LF } & 87 & 78 & 67 & 59 \\ \text { HF } & 29 & 25 & 16 & 15\end{array}$

Fig. 1 Survival curves for comparing the high-ferritin (HF) and low-ferritin (LF) groups. Black and dotted lines indicate the HF and LF groups, respectively. The prognosis was significantly worse in the HF group (log-rank test, $p=0.009$ ) 
Table 3 Multivariate analysis of all-cause mortality and cardiovascular events

\begin{tabular}{llllll}
\hline Variables & \multicolumn{2}{l}{ All-cause mortality } & & \multicolumn{2}{l}{ CV events } \\
\cline { 2 - 3 } \cline { 5 - 6 } & HR $(95 \% \mathrm{Cl})$ & $p$ value & & HR $(95 \% \mathrm{Cl})$ & $p$ value \\
\hline Age, year & $1.09(1.04-1.12)$ & $<0.001$ & & $1.04(1.00-1.09)$ & 0.027 \\
Male & $0.84(0.40-1.77)$ & 0.64 & & $0.63(0.23-1.75)$ & 0.36 \\
HD vintage, month & $1.00(0.99-1.00)$ & 0.12 & & $1.00(0.99-1.00)$ & 0.33 \\
Ferritin $>100 \mathrm{ng} / \mathrm{mL}$ & $2.49(1.21-5.12)$ & 0.018 & & $2.69(1.12-6.46)$ & 0.034 \\
CRP, mg/dl & $1.01(0.87-1.13)$ & 0.85 & & $1.00(0.78-1.16)$ & 0.99 \\
History of CV events & $1.20(0.88-1.14)$ & 0.36 & & $1.11(0.44-2.82)$ & 0.82 \\
\hline
\end{tabular}

$C V$ cardiovascular, $H D$ hemodialysis, $C R P$ C-reactive protein

the most common cause of death in both groups [30\% (9 of 23 events) in the LF and 40\% (6 of 15 events) in the HF groups]. On ROC analysis, ferritin level of $102 \mathrm{ng} / \mathrm{mL}$ provided the highest Youden index to predict all-cause death (Additional file 1: Figure S1) with area under the curve of $0.57(p=0.48)$. According to the Kaplan-Meier survival curves, the HF group had significantly poor survival compared with the LF group (log-rank test, $p=0.009$, Fig. 1). In univariate analysis, age, serum iron, TIBC, ESA dose, serum creatinine, serum albumin, CRP, history of atrial fibrillation, history of cardiovascular events, gastrectomy, malignancy and liver disorders, and recent hospitalization were related to increased mortality (Additional file 2: Table S1). In multivariate analysis, after adjusting for age, gender, hemodialysis vintage, CRP levels, and history of cardiovascular events, ferritin levels $>100 \mathrm{ng} / \mathrm{mL}$ were independently associated with all-cause mortality $(p=0.018$, Table 3$)$. The HR was 2.49 (95\% confidence interval (CI), 1.21-5.12). The results did not change even if patients with chronic inflammation (defined by history of malignancy and liver disorders, and

Table 4 Secondary endpoints (cardiovascular events and infection-related hospitalizations) in low- and high-ferritin patients

\begin{tabular}{llll}
\hline Secondary endpoints & $\begin{array}{l}\text { Total } \\
(n=116)\end{array}$ & $\begin{array}{l}\text { LF } \\
(n=87)\end{array}$ & $\begin{array}{l}\text { HF } \\
(n=29)\end{array}$ \\
\hline CV events & 23 & 13 & 10 \\
AMl & $4(17 \%)$ & $2(15 \%)$ & $2(20 \%)$ \\
Cerebral infarction & $13(57 \%)$ & $8(62 \%)$ & $5(50 \%)$ \\
Cerebral hemorrhage & $6(26 \%)$ & $3(23 \%)$ & $3(30 \%)$ \\
Infection-related hospitalizations & 36 & 25 & 11 \\
Bacteremia and sepsis & $10(28 \%)$ & $8(32 \%)$ & $2(18 \%)$ \\
Pulmonary & $11(31 \%)$ & $6(24 \%)$ & $5(45 \%)$ \\
Gastrointestinal and hepatobiliary & $7(19 \%)$ & $5(20 \%)$ & $2(18 \%)$ \\
Skin and soft tissue & $7(19 \%)$ & $5(20 \%)$ & $2(18 \%)$ \\
Bone and joint & $1(2.8 \%)$ & $1(4 \%)$ & $0(0 \%)$ \\
\hline
\end{tabular}

LF low-ferritin, $H F$ high-ferritin, $C V$ cardiovascular, $A M I$ acute myocardial infarction recent hospitalization within three months) were excluded (Additional file 3: Figure S2).

\section{Secondary endpoints}

During the follow-up period, 13 of 87 patients (15\%) and 10 of 29 patients (34\%) experienced cardiovascular events, among which cerebral infarction was the most common, followed by cerebral hemorrhage and AMI. Detailed results are shown in Table 4. The HF group experienced a higher number of cardiovascular events than the LF group (log-rank test, $p=0.016$, Fig. 2). In univariate analysis, age, iron dose, and history of liver disorders were related to cardiovascular events (Additional file 2: Table S1). In the multivariate analysis, ferritin levels $>100 \mathrm{ng} / \mathrm{mL}$ were also independently related to cardiovascular events, after adjusting for the same confounding factors as those for the primary endpoint (i.e., age, gender, hemodialysis vintage, CRP levels, and history of cardiovascular events; HR 2.69; 95\% CI 1.12-6.46; $p=0.034$; Table 3). Regarding infection-related hospitalizations, 25 of 87 patients (29\%) in the LF and 11 of 29 patients (38\%) in the HF groups were recorded. No statistical significance was found (logrank test, $p=0.17$; Table 4 , Fig. 2). These results again were the same after exclusion of patients with chronic inflammation (Additional file 4: Figure S3).

\section{Discussion}

In this single-center retrospective cohort study, ferritin levels $>100 \mathrm{ng} / \mathrm{mL}$ were related with poor long-term survival in MHD patients, even after adjusting for age, gender, hemodialysis vintage, CRP levels, and history of cardiovascular events. Elevated ferritin levels were also associated with increased cardiovascular events.

Several studies [6-9] have suggested that high ferritin levels are related to an unfavorable prognosis in different MHD patient populations (Table 5). In our study and another study from Japan, the cut-off ferritin level was $100 \mathrm{ng} / \mathrm{mL}$, whereas in other countries [6-8], the cut-off ferritin level was $600-1200 \mathrm{ng} / \mathrm{mL}$. The different cut-off values despite the same relationship between hyperferritinemia and poor prognosis may be due to the significantly different distribution of serum ferritin among dialysis patients in Japan and other countries [14]. The mean serum ferritin level was $144.31 \mathrm{ng} / \mathrm{mL}$ in Japan [15], and $>50 \%$ MHD patients had ferritin levels of $>$ $800 \mathrm{ng} / \mathrm{mL}$ in the USA [14]. This may be caused by potential racial differences [16], differences in iron and ESA doses [14], and/or the presence of chronic inflammation related to the dialysis catheter [17]. Japanese MHD patients have approximately twice better survival compared with patients from other regions [18]. Given the better prognosis and low ferritin levels in Japanese MHD patients, the low serum ferritin levels, or causative 

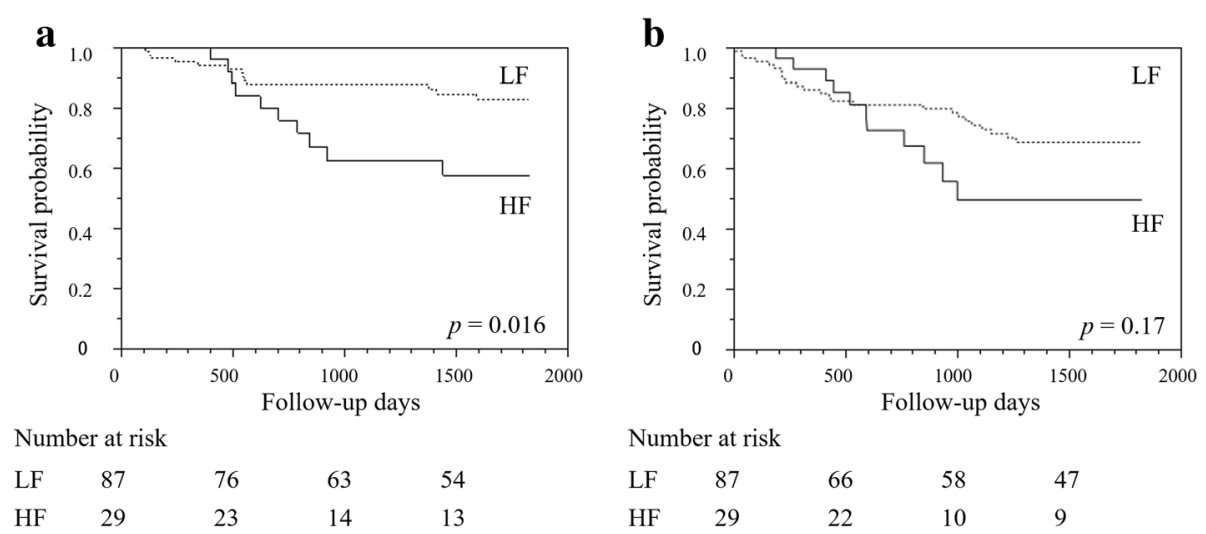

Fig. 2 Kaplan-Meier curves of cardiovascular events (a) and infection-related hospitalizations (b). Black and dotted lines indicate the high-ferritin (HF) and low-ferritin (LF) groups, respectively. The HF group experienced a significantly higher number of cardiovascular events than did the LF group (log-rank test, $p=0.016)$

factors determining ferritin levels, may partially explain the low mortality in Japanese MHD patients.

To determine the frequency of the various causes of death in MHD patients with high ferritin levels, we reviewed the details of all deaths, which revealed that cardiovascular events and infections were the two leading causes. Several reports have demonstrated the association of cardiovascular events and infections with hyperferritinemia. Analysis of a nationwide database based on an increased trend of ferritin levels identified increased cardiovascular events in patients on MHD ( $n$ =1086) [10]. Another clinical study suggested that the ferritin level in ESRD patients was correlated with the carotid intima-media thickness, which reflects the extent of atherosclerosis [19]. Our study demonstrated that cardiovascular events, either fatal or non-fatal, increased (HR, 2.69) with ferritin levels, even after adjusting age, sex, vintage of hemodialysis, CRP levels, and history of

Table 5 Ferritin and all-cause mortality in MHD patients

\begin{tabular}{|c|c|c|c|}
\hline $\begin{array}{l}\text { Author } \\
\text { (published) }\end{array}$ & Population & $\begin{array}{l}\text { Cut-off of } \\
\text { ferritin }(\mathrm{ng} / \mathrm{mL})\end{array}$ & Result \\
\hline $\begin{array}{l}\text { Kletzmayr } \\
\text { (2002) [6] }\end{array}$ & $\begin{array}{l}\text { Austria } \\
n=100\end{array}$ & 600 & $\begin{array}{l}\text { HR of all-cause mortality } \\
\text { increased in ferritin } \\
>600 \mathrm{ng} / \mathrm{mL}\end{array}$ \\
\hline $\begin{array}{l}\text { Kalantar- } \\
\text { Zadeh } \\
(2005)[7]\end{array}$ & $\begin{array}{l}\text { the USA } \\
n=58,058\end{array}$ & $\begin{array}{l}\text { N/A } \\
\text { (12 groups) }\end{array}$ & $\begin{array}{l}\text { HR of all-cause mortality } \\
\text { increased in ferritin } \\
>1200 \mathrm{ng} / \mathrm{mL}\end{array}$ \\
\hline $\begin{array}{l}\text { Jenq } \\
\text { (2009) [8] }\end{array}$ & $\begin{array}{l}3 \text { centers } \\
\text { in Taiwan } \\
n=187\end{array}$ & 200,700 & $\begin{array}{l}\text { More all-cause mortality } \\
\text { in ferritin }>700 \mathrm{ng} / \mathrm{mL} \\
\text { than in two other groups }\end{array}$ \\
\hline $\begin{array}{l}\text { Hasuike } \\
(2010)[9]\end{array}$ & $\begin{array}{l}7 \text { centers } \\
\text { in Japan } \\
n=94\end{array}$ & 100 & $\begin{array}{l}\text { HR of all-cause mortality } \\
\text { was } 4.18 \mathrm{in} \mathrm{ferritin} \\
>100 \mathrm{ng} / \mathrm{mL}\end{array}$ \\
\hline This study & $\begin{array}{l}\text { A single } \\
\text { center in } \\
\text { Japan } \\
n=116\end{array}$ & 100 & $\begin{array}{l}\text { HR of all-cause mortality } \\
\text { was } 2.49 \mathrm{in} \text { ferritin } \\
>100 \mathrm{ng} / \mathrm{mL}\end{array}$ \\
\hline
\end{tabular}

MHD maintenance hemodialysis cardiovascular events. Regarding infections, a previous study described three times higher risk of bacterial infections in hemodialysis patients with higher ferritin levels [20]. Our study did not find such a correlation between hyperferritinemia and infection-related hospitalization.

The causality for elevated ferritin and increased all-cause mortality remains to be explored. One explanation is that the underlying cause of elevated ferritin levels is associated with poor survival (i.e., ferritin is a surrogate marker of prognosis in MHD patients). Ferritin is elevated not only by stored iron but also by inflammation, infection, malignancy, and liver diseases [21]. In our study, all the factors that may alter ferritin levels, including CRP levels, presence of malignancy, and liver diseases, did not differ between the LF and HF groups. CRP was also not independently correlated with prognosis in multivariate analysis. The results did not change even if we excluded patients with history of malignancy and liver disorders, and recent hospitalization, which was compatible with previous reports [9]. Ferritin may be a surrogate marker of prognosis in MHD patients that cannot be detected by evaluating past medical histories listed above or CRP levels. Whether ferritin itself or the comorbidities underlying elevated ferritin levels are the cause of a poor prognosis in MHD patients remains to be studied.

Our study had several limitations. First, the number of samples was small. We observed 38 primary endpoint events, which allowed six factors as a reasonable maximum number to perform the multivariate analysis. There might be a possibility that this adjusting of confounding factors was not sufficient to evaluate the association between ferritin levels and outcomes because of our study sample size. However, we have carefully examined the selection of variables that should be adjusted based on previous studies [7,9] as well as backgrounds of the cohort. We assume that this study has 
substantially adjusted confounding factors. Second, this was a single-center study. The population may be biased by the baseline characteristics of the patients in our hospital. However, as shown in Table 1, in terms of major demographic baseline characteristics of the patients, for example, age, sex, and vintage of hemodialysis, our cohort showed similar characteristics with data reported in Japanese MHD national survey [22]. Although prospective larger studies assessing ferritin levels and prognosis or causes of death are warranted, our study clarified the association between high ferritin levels $>100 \mathrm{ng} / \mathrm{mL}$ and mortality and cardiovascular events in MHD patients. This result will potentially help to assess both mortality and cardiovascular risks and to improve prognosis in MHD patients.

In conclusion, in patients receiving MHD, ferritin levels $>100 \mathrm{ng} / \mathrm{mL}$ were associated with increased rates of all-cause mortality and cardiovascular events.

\section{Additional files}

Additional file 1: Figure S1. The Receiver Operating Characteristic (ROC) analysis for all-cause mortality. The best Youden index was observed at cut-off level of ferritin of $102 \mathrm{ng} / \mathrm{mL}$ (area under the curve 0.57, $p=0.48$ ). (TIF $306 \mathrm{~kb}$ )

Additional file 2: Table S1. Univariate analysis of all-cause mortality and cardiovascular events (DOCX $37 \mathrm{~kb}$ )

Additional file 3: Figure S2. Survival curves for comparing the highferritin (HF) and low-ferritin (LF) groups after exclusion of patients with chronic inflammation. Black and dotted lines indicate the HF and LF groups, respectively. The prognosis was significantly worse in the HF group (log-rank test, $p=0.014$ ). (TIF $189 \mathrm{~kb}$ )

Additional file 4: Figure S3. Kaplan-Meier curves of cardiovascular events (a) and infection-related hospitalizations (b) after exclusion of patients with chronic inflammation. Black and dotted lines indicate the high-ferritin (HF) and low-ferritin (LF) groups, respectively. The HF group experienced a significantly higher number of cardiovascular events than did the LF group (log-rank test, $p=0.004$ ). (TIF $369 \mathrm{~kb}$ )

\section{Acknowledgements}

Not applicable.

\section{Funding}

Not applicable.

\section{Availability of data and materials}

The data will not be shared because the informed consent from the subjects regarding the public availability for their personal data was not obtained.

\section{Authors' contributions}

Research idea and study design: RS, TF, TK; data acquisition: RS, TF, FT, MF, MN (Masahiko Nagahama), YK; data analysis/interpretation: RS, TF, TK; supervision or mentorship: TF, TK, MN (Masaaki Nakayama), YK. Each author contributed important intellectual content during manuscript drafting or revision and accepts accountability for the overall work by ensuring that questions pertaining to the accuracy or integrity of any portion of the work are appropriately investigated and resolved. All authors read and approved the final manuscript.

\section{Ethics approval and consent to participate}

All procedures performed in studies involving human participants were in accordance with the ethical standards of the institutional research committee at which the studies were conducted (IRB approval number 14-J010) and with the 1964 Helsinki declaration and its later amendments or comparable ethical standards. We provided all individual patients with the option to opt out of participation.

\section{Consent for publication}

Not applicable.

\section{Competing interests}

Honoraria: YK received lecture fees from Chugai Pharmaceutical Co., Ltd. Other authors have declared that no competing interest exists.

\section{Publisher's Note}

Springer Nature remains neutral with regard to jurisdictional claims in published maps and institutional affiliations.

\section{Author details}

'Department of Nephrology, St. Luke's International Hospital, 9-1 Akashi-cho, Chuo-ku, Tokyo 104-8560, Japan. ${ }^{2}$ Center for Clinical Epidemiology, St. Luke's International University, Tokyo, Japan. ${ }^{3}$ Department of Healthcare Quality and Safety, Graduate School of Medicine, Gunma University, Gunma, Japan.

Received: 20 September 2018 Accepted: 8 April 2019

Published online: 08 May 2019

\section{References}

1. Kidney Disease. Improving global outcomes (KDIGO) Anemia work group. KDIGO Clinical practice guideline for anemia in chronic kidney disease. Kidney Int Suppl. 2012;2:279-335.

2. Tsukamoto T, Matsubara T, Akashi Y, Kondo M, Yanagita M. Annual iron lost in hemodyalisis. Am J Nephrol. 2016:43:32-8.

3. Diseases K. KDOQI clinical practice guidelines and clinical practice recommendations for anemia in chronic kidney disease. Am J Kidney Dis. 2006:47:S11-145.

4. Tsubakihara Y, Nishi S, Akiba T, Hirakata H, Iseki K, Kubota M, et al. 2008 Japanese society for dialysis therapy: guidelines for renal anemia in chronic kidney disease. Ther Apher Dial. 2010;14:240-75.

5. 2015 JSDT quideline for renal anemia in chronic kidney disease. J Japanese Soc Dial Ther 2016;49:89-158.

6. Kletzmayr J, Hörl WH, Horl WH. Iron overload and cardiovascular complications in dialysis patients. Nephrol Dial Transplant. 2002;17(Suppl 2): 25-9.

7. Kalantar-Zadeh K, Regidor DL, McAllister CJ, Michael B, Warnock DG. Timedependent associations between Iron and mortality in hemodialysis patients. J Am Soc Nephrol. 2005;16:3070-80.

8. Jeng C-C, Hsu C-W, Huang W-H, Chen K-H, Lin J-L, Lin-Tan D-T. Serum ferritin levels predict all-cause and infection-cause 1-year mortality in diabetic patients on maintenance hemodialysis. Am J Med Sci. 2009;337: 188-94.

9. Hasuike $Y$, Nonoguchi $H$, Tokuyama M, Ohue M, Nagai T, Yahiro M, et al. Serum ferritin predicts prognosis in hemodialysis patients: the Nishinomiya study. Clin Exp Nephrol. 2010;14:349-55.

10. Kuragano T, Matsumura O, Matsuda A, Hara T, Kiyomoto H, Murata T, et al. Association between hemoglobin variability, serum ferritin levels, and adverse events/mortality in maintenance hemodialysis patients. Kidney Int Nature Publishing Group: 2014;86:845-54.

11. Shoji T, Niihata K, Fukuma S, Fukuhara S, Akizawa T, Inaba M. Both low and high serum ferritin levels predict mortality risk in hemodialysis patients without inflammation. Clin Exp Nephrol. 2016;21:1-9.

12. Dekker FW, De Jager DJ, Vervloet MG, Dekker FW. Noncardiovascular mortality in CKD: an epidemiological perspective. Nat Rev Nephrol. 2014;10: 208-14.

13. Youden WJ. Index for rating diagnostic tests. Cancer. 1950;3:32-5.

14. Bailie GR, Larkina M, Goodkin DA, Li Y, Pisoni RL, Bieber B, et al. Variation in intravenous iron use internationally and over time: the dialysis outcomes and practice patterns study (DOPPS). Nephrol Dial Transplant. 2013;28:2570-9.

15. Nakai S, Hanafusa N, Masakane I, Taniguchi M, Hamano T, Shoji T, et al. An overview of regular dialysis treatment in Japan (as of 31 December 2012). Ther Apher Dial. 2014;18:535-602

16. Zacharski LR, Ornstein DL, Woloshin S, Schwartz LM. Association of age, sex, and race with body iron stores in adults: analysis of NHANES III data. Am Heart J. 2000;140:98-104. 
17. Wish JB. Assessing iron status: beyond serum ferritin and transferrin saturation. Clin J Am Soc Nephrol. 2006;1 (Suppl 1):4-8.

18. Robinson BM, Bieber B, Pisoni RL, Port FK. Dialysis outcomes and practice patterns study (DOPPS): its strengths, limitations, and role in informing practices and policies. Clin J Am Soc Nephrol. 2012;7:1897-905.

19. Reis KA, Guz G, Ozdemir H, Erten Y, Atalay V, Bicik Z, et al. Intravenous iron therapy as a possible risk factor for atherosclerosis in end-stage renal disease. Int Heart J. 2005;46:255-64.

20. Teehan GS, Ruthazer R, Balakrishnan VS, Snydman D, Jaber BL. Iron storage indices and risk of bacterial infections in hemodialysis patients. Hemodial Int. 2004:8:226-32.

21. Kalantar-Zadeh K, Kalantar-Zadeh K, Lee GH. The fascinating but deceptive ferritin: to measure it or not to measure it in chronic kidney disease? Clin $J$ Am Soc Nephrol. 2006;1(Suppl 1):9-18.

22. http://docs.jsdt.or.jp/overview/pdf2016/2015all.pdf. Accessed 11/5/2017.

Ready to submit your research? Choose BMC and benefit from:

- fast, convenient online submission

- thorough peer review by experienced researchers in your field

- rapid publication on acceptance

- support for research data, including large and complex data types

- gold Open Access which fosters wider collaboration and increased citations

- maximum visibility for your research: over $100 \mathrm{M}$ website views per year

At BMC, research is always in progress.

Learn more biomedcentral.com/submissions 